\title{
A APLICAÇÃO DOS NUDGES NA PRESERVAÇÃO DO LIVRE ARBÍTRIO EM AUDIÊNCIAS JUDICIAIS DE CONCILIAÇÃO E MEDIAÇÃO
}

\author{
Denise Lage Bezerra Weyne *
}

\begin{abstract}
RESUMO
O presente artigo analisa os institutos da conciliação e mediação judicial e a correlata legislação que determina a imposição de multa para o não comparecimento injustificado das partes à audiência de conciliação e mediação. Sugere-se que a saída para a valorização dos meios consensuais que mais se coaduna com suas características é o paternalismo libertário e não o intervencionismo estatal. Conclui que a utilização de simples estratégias pode trazer a tão esperada mudança de mentalidade social da cultura demandista, pois através dos nudges consegue-se chegar ao ápice das características dos meios consensuais.
\end{abstract}

PALAVRAS-CHAVE: Conciliação. Mediação. Nudge. Paternalismo libertário. Livre arbítrio.

\section{THE APPLICATION OF NUDGES IN PRESERVATION OF FREE WILL IN JUDICIAL CONCILIATION AND MEDIATION HEARINGS}

\begin{abstract}
This article examines the institutes of conciliation and judicial mediation and the related legislation that imposes a fine for unjustified non-attendance of the parties at the conciliation and mediation hearing. It is suggested that the way out for the appreciation of the consensual means that best fits their characteristics is libertarian paternalism and not state interventionism. It concludes that the use of simple strategies can bring about the longawaited change in the social mindset of the demand culture, because through nudges it is possible to reach the apex of the characteristics of the consensual means.
\end{abstract}

KEYWORDS: Conciliation. Mediation. Nudge Libertarian paternalism. Free will.

\section{INTRODUÇÃO}

Ao se deparar com um conflito, o indivíduo pode se socorrer de algumas opções: tentar inicialmente resolver a celeuma com a parte adversa exaurindo a seara extrajudicial ou buscar o Poder Judiciário mediante o ajuizamento de uma demanda. Nesta segunda hipótese, o sistema traz uma nova chance para que a solução da pendência se resolva pelo contato das

\footnotetext{
* Mestranda em Direito pelo Programa de Mestrado em Direito do Centro Universitário Christus (UNICHRISTUS). Advogada. Pós graduada em Direito de Família de Sucessões. Pós graduada em Direito do Trabalho e Processo do Trabalho. Bacharela em Direito pela Universidade Federal do Ceará (UFC). Email: deniselage0509@gmail.com
} 
partes: é que, por regra, o primeiro ato judicial será a determinação de citação do promovido para que compareça à audiência de conciliação e mediação.

Ao receber a carta ou mandado de citação, o réu fica ciente de que deve comparecer à citada audiência e que a contagem do prazo de contestação somente se inicia após a audiência e na hipótese de nesta não ter produzido um acordo que porá fím ao conflito existente entre as partes. Todavia, na mesma carta ou mandado, constará a advertência de que caso o citando não compareça ao ato de forma injustificada, incorrerá no pagamento de multa.

No primeiro tópico do trabalho será analisada a mediação e a conciliação, que são os principais meios consensuais aplicados no processo judicial, passando pelos conceitos, diferenças, vantagens, além do exame destes institutos no atual Código de Processo Civil.

Em seguida, será examinada a teoria do nudge, que é fenômeno advindo da economia comportamental e tem aplicação sobre as pessoas quando estas precisam fazer escolhas. Como o nudge é incentivo para o bem, serão abordados exemplos de aplicação prática nos comportamentos socialmente recomendáveis.

No terceiro tópico, abordar-se-á a teoria dos jogos e algumas técnicas adotadas nos meios consensuais, com foco nas expectativas matemáticas que norteiam as partes envolvidas por ocasião das tratativas do acordo na audiência de conciliação e mediação, através do relativismo do "ganhar" e "perder". Na última parte, através de uma análise conjugada de todos os tópicos anteriores, será examinado o uso de nudges no livre arbítrio da eleição dos meios consensuais.

Desta feita, o trabalho visa a examinar a aplicação de nugdes e paternalismo libertário nos meios consensuais, em comparação ao modelo processual hoje vigente, como garantia do livre arbítrio e da voluntariedade que devem nortear os citados meios.

O trabalho se pautará em pesquisa exploratória bibliográfica, através de estudo de livros, artigos acadêmicos, ambos nas versões impressas e eletrônicas, além da legislação, todos ligados ao tema de nudges e meios consensuais de resolução de conflitos. A metodologia é hipotética dedutiva e os resultados serão apresentados de forma qualitativa.

\section{MEDIAÇÃO E CONCILIAÇÃO JUDICIAL}

Os meios autocompositivos tiveram importante valorização com a vigência do atual Código de Processo Civil e a lei de mediação $n^{\circ}$ 13.140/2015 e neste sentido, a regra processual civil é a de que antes da apresentação de contestação pelo réu, deve ser designada 
audiência de conciliação e mediação. Somente se esta for inexitosa, é que o promovido apresentará sua defesa.

Diversas vantagens podem ser apontadas pela adoção da estratégia legal acima dita, como o fato de as partes chegarem à audiência inicial mais propensas a um acordo, em face da não apresentação de defesa pelo réu e dos correlatos argumentos impeditivos, modificativos ou extintivos do direito do promovente.

Os meios consensuais mostram-se, ainda, como uma alternativa de combate à "cultura demandista ou judiciarista que instalou-se na sociedade brasileira, e, segue presente, em boa parte por conta de uma leitura exarcebada, quiçá ingênua e irrealista da garantia de acesso à justiça” (MANCUSO, 2009, p. 98).

O Conselho Nacional de Justiça, por sua vez, editou o Manual de Mediação Judicial, trazendo como hipóteses de meios autocompositivos: negociação, mediação, conciliação, arbitragem, med-arb e outras hibridações de processos e práticas autocompositivas inominadas, como as oficinas de parentalidade.

Desta maneira, é notória a importância dos meios alternativos como forma de solução de conflitos no ordenamento jurídico atual, tendo em vista diversas vantagens que podem ser destacadas como rapidez na finalização do processo, economia de custos, maior participação das partes na formação da solução e por conseguinte, a menor incidência de descumprimento dos acordos, se comparado a decisões judiciais impositivas.

Os principais meios consensuais empregados na via judicial e que utilizam a figura do terceiro imparcial são a conciliação e a mediação. A Resolução 125 de 2010 do CNJ, por sua vez, disciplinou a política judiciária nacional de tratamento adequado dos conflitos de interesses no âmbito do Poder Judiciário, trazendo a formação técnica dos mediadores e conciliadores, além da criação dos núcleos permanentes de métodos alternativos de solução de conflitos.

A mediação é meio autocompositivo que utiliza a figura do terceiro imparcial para que as partes retomem a comunicação interrompida e possam construir a solução do impasse. Assim, a função do mediador não é sugerir propostas, mas sim, fomentar o diálogo entre os interessados.

O parágrafo único do artigo $1^{\circ}$ da lei de mediação (13.140/2015) conceitua tal meio como "a atividade técnica exercida por terceiro imparcial sem poder decisório, que, escolhido pelas partes, as auxilia e estimula a identificar ou desenvolver soluções consensuais para a controvérsia” (BRASIL, 2015). 
Barbosa (2015, p. 41) apresenta conceito mais extenso para a mediação, destacando que o dever do mediador é fomentar às partes a exercer suas escolhas, como se pode verificar do trecho abaixo:

\begin{abstract}
A mediação é munida de linguagem própria, que representa o avesso da linguagem da conciliação e da arbitragem. A mediação é um método fundamentado teórica e tecnicamente, por meio do qual uma terceira pessoa, neutra e especialmente treinada, ensina os mediandos a despertarem seus recursos pessoais para que consigam transformar o conflito em oportunidades de construção de outras alternativas, para o enfrentamento ou a prevenção do conflito. $\mathrm{O}$ mediador não decide pelos mediandos, já que a essência dessa dinâmica é permitir que as partes envolvidas em conflito ou impasses resgatem a responsabilidade por suas próprias escolhas.
\end{abstract}

Esta característica da mediação, de que o terceiro imparcial deve deixar a cargo das partes a responsabilidade da escolha da solução, advém da natureza dos conflitos que são submetidos a esta espécie de meio consensual. É que o mediador atuará preferencialmente nos casos em que houver vínculo anterior entre as partes, como as ações de família.

Considerando que a relação pessoal existente entre os mediados permanecerá no curso processual e até após a finalização da ação judicial em que se discute o conflito, somente as partes, dentro de sua relação, poderão formular propostas que trarão fim definitivo ao impasse. Por esta razão, prega-se que na mediação não é oportuna a sugestão de propostas pelo terceiro imparcial às partes.

Já o conciliador, atuará preferencialmente nos casos em que não houver vínculo anterior entre as partes, e poderá sugerir soluções para o litígio, sendo vedada a utilização de qualquer tipo de constrangimento ou intimidação para que as partes conciliem (art. 165, 2º, CPC). Como exemplo de tais situações, pode-se citar ação indenizatória por acidente de trânsito ou por relação de consumo, visto que são relações esporádicas.

Através de técnicas adequadas, o conciliador tem como objetivo a chegada de um acordo, mediante uma intervenção mais direta na formulação das propostas discutidas. $\mathrm{O}$ Manual de Mediação do CNJ traz diversas diferenças entre a conciliação e a mediação, podendo-se destacar que:

i) a mediação visaria à resolução do conflito enquanto que a conciliação buscaria apenas o acordo; ii) a mediação visaria à restauração da relação social subjacente ao caso enquanto que a conciliação buscaria o fim do litígio;iii) a mediação partiria de uma abordagem de estímulo (ou de facilitação) do entendimento enquanto a conciliação permitiria a sugestão de uma proposta de acordo pelo conciliador; iv) a mediação seria, em regra, mais demorada e envolveria diversas sessões enquanto a conciliação seria um processo mais breve com apenas uma sessão; v) a mediação seria voltada às pessoas e teria o cunho preponderantemente subjetivo enquanto a conciliação seria voltada aos faz e direitos e com enfoque essencialmente objetivo. 
O citado Manual de Mediação também examina os fundamentos da negociação, trazendo técnicas e orientações para uma negociação distributiva eficiente, assim como o procedimento da mediação desde a preparação até a resolução das questões. Houve a preocupação até mesmo com o tipo da mesa a ser usada nas sessões e a disposição das cadeiras: se mesa redonda, retangular ou sem mesa, visando sempre à equidistância das partes em ambiente informal.

Vasconcelos (2017, p. 208) ressalta a importância do acolhimento que o mediador deve ter em relação às partes, ao dispor que "é de responsabilidade do(s) mediador(es) chegar(em) com antecedência às reuniões, para verificar as condições ambientais, providenciar papéis e canetas para as devidas anotações (...)"

Todas as providências acima exemplificadas têm por objetivo a construção de ambiente propício para a chegada do acordo e no próximo tópico, será analisada a aplicação de nudges na audiência de conciliação e mediação prevista no artigo 334, do Código de Processo Civil (BRASIL, 2015).

\section{NUGDES E ESTÍMULO A DESEJÁVEIS COMPORTAMENTOS SOCIAIS}

Os nudges são "empurrões” de incentivo oriundos da economia comportamental. São estratégias utilizadas para estimular pessoas a seguirem comportamentos socialmente interessantes. Como exemplo, pode-se citar a disposição dos alimentos na fila de um refeitório escolar. Se a intenção é incentivar os estudantes a consumirem mais frutas, é recomendável colocar estes alimentos em local de destaque e em maior proporção. E esta é exatamente a grande vantagem dos nudges: a influência para o bem.

Como se pode observar, os nudges auxiliam pessoas a escolherem um bom comportamento, quando estas têm um rol de escolhas a decidir. Quem realiza esta manipulação, visando à influência, é chamado arquiteto de escolhas. É o caso do coordenador que determina a ordem de disposição dos alimentos no refeitório escolar, do exemplo acima citado.

Quando a intenção do arquiteto de escolhas é para o mal, já não se trata mais de nudge, mas slude. É a oferta de guloseimas no corredor de espera das filas de supermercados, por exemplo, em que as pessoas são atraídas a consumir estes alimentos quando estão ociosas e ansiosas para finalizar suas compras e assim, acabam agindo pelo impulso ao comprar chocolates, por exemplo. 
Os nudges e sludes estão presentes no dia a dia do ser humano, desde as mais simples decisões até as mais complexas. Situam-se na esfera do chamado paternalismo libertário, que é ideia de liberdade de escolha dos indivíduos, que podem ser influenciadas pelos arquitetos de escolhas.

O paternalismo libertário não deve ser entendido como uma manipulação, mas um incentivo capaz de preservar o livre arbítrio das pessoas, até mesmo porque em alguns momentos, pode-se agir por impulso e tomar posturas equivocadas. O que se observa é que quanto maior o leque de opções, mais difícil é a escolha e daí vem o grande valor dos nudges, que é o de ajudar na decisão pela melhor escolha.

Entretanto, a regra é que quem defende a liberdade de escolha plena, repudia a influência dos nudges, como se não existissem limitadores ao discernimento dos indivíduos como impulso e a inexperiência técnica em determinada matéria. Ademais, quanto maior o número de opções, mais difícil se torna a escolha, acoplando-se o medo de arrependimento e a indecisão, o que mostra paralisia e risco de frustração. Assim, é mais coerente aderir ao paternalismo libertário do que aceitar imposições estatais, por exemplo.

Veja-se o quanto seria efetivamente libertador seria, dentro de um universo de escolhas, ter auxílio na busca da melhor opção, sendo possível discernir entre um nudge e um slude, ao invés de ser submetido a uma ordem estatal arbitrária. Dessa maneira, "se os nudges substituírem exigências e proibições, o Estado se tornará menor e mais modesto" (THALER; SUNSTEIN, 2019, p. 23).

Para melhor compreender os nudges, é importante traçar as diferenças entre o sistema automático e o sistema reflexivo. O primeiro tem como característica guiar-se pelo inconsciente, intuitivo e se liga a tarefas que demandam menor uso cerebral, geralmente atreladas ao hábito, como o modo de tomar banho, por exemplo. Já o sistema reflexivo, é mais lento e controlado, e retrata escolhas que precisam de discernimento mais apurado.

Nas palavras de Kahneman (2012, p. 30) "a maior parte do que você (seu Sistema 2) pensa e faz origina-se de seu Sistema 1, mas o Sistema 2 assume o controle quando as coisas ficam difíceis, e normalmente ele tem a última palavra", cabendo ressaltar que o estudioso classifica o sistema 1 como automático e sistema 2 como o reflexivo.

Assim, o mais simples seria que as pessoas recorressem sempre ao automático e os nudges seriam excelentes balizadores do sistema 1 para a adoção da boa escolha, inclusive na contenção dos tentadores impulsos e as decisões tomadas no calor da emoção. Da interação entre o sistema reflexivo e o automático, ligando-se o impulsivo ou planejador, podem-se citar 
três regras gerais: ancoragem, disponibilidade e representatividade. A ancoragem é uma espécie de margem de escolha, cujo processo inicia através de negociação de um valor e depois de sucessivos ajustes, chega-se a uma solução. A disponibilidade se refere a riscos e o grau de preocupação das pessoas com estes, a depender das experiências que cada uma tenha como os referidos riscos. Já a representatividade, demonstra dificuldade em se estabelecer padrões, pois determinadas ocorrências podem ser apenas coincidências.

É imperioso destacar a influência que um grupo pode exercer no indivíduo, justificada pela busca da conformidade que pessoas buscam nas outras. É o chamado efeito da manada e assim, bons ou maus comportamentos podem ser incentivados pelo arquiteto das escolhas. Como prova da influência social, cita-se o poder da divulgação de pesquisas eleitorais às vésperas dos dias de votação, na mostra de que a campanha já está "ganha" pelo candidato X. A decisão da maioria, retratada pelo resultado da pesquisa divulgada pela mídia, atinge o público indeciso para que este siga a maioria.

Nesta perspectiva, observam-se os nudges sociais. Como hipótese de aplicação destes, pode-se citar o exemplo retratado na obra de Thaler e Sunstein (2019, p. 80):

\begin{abstract}
No contexto do cumprimento das obrigações fiscais, um experimento aplicado no mundo real pelo governo de Minnesota produziu grandes mudanças de comportamento. Grupos de contribuintes receberam quatro tipos de informação. Um deles ficou sabendo que seus impostos eram destinados a boas causas, como educação, policiamento e serviços dos bombeiros. Outros sofreram ameaças com informações sobre os riscos de punição caso fraudassem o fisco. Outro grupo foi instruído sobre como obter ajuda caso tivessem dúvidas ou dificuldades para preencher os formulários. E, por fim, um grupo recebeu a informação de que mais de $90 \%$ dos moradores de Minnesota pagavam os impostos e estavam em dia com o fisco. Só uma dessas intervenções exerceu um efeito significativo: a última. Ao que parece, alguns contribuintes eram mais propensos a descumprir a lei devido a uma percepção equivocada - plausivelmente baseada no grande número de relatos de sonegação fiscal veiculado por meios de comunicação ou por outros modos - de que o percentual de cidadãos cumpridores da lei é bastante baixo. Quando recebem a informação de que o nível de cumprimento da lei é ato, eles se tornam menos propensos a burlar o fisco. Disso se depreende que é possível fomentar comportamentos tanto desejáveis quanto indesejáveis, pelo menos até certo ponto, apenas chamando a atenção da população para o que os outros estão fazendo.
\end{abstract}

Assim, utilizando-se o comportamento da manada como nudge social, também é possível incentivar parte dos demais membros da sociedade, ao se demonstrar as boas práticas exercidas por alguns. Em situações sem feedback de outras pessoas, assim como as difíceis e aquelas que têm efeito diferidos demonstram maior dificuldade de ser tomadas, importando o nudge em auxílio efetivo para o público atingido.

Nesta seara de indecisão, algumas pessoas quedam inertes e o mercado aproveita-se desse comportamento para obter lucro, mediante estratégias como a cortesia inicial da 
assinatura de uma revista e posterior renovação automática. Estas pessoas demonstram a opção do menor esforço ao adotarem a postura padrão de permanecer vinculadas à revista, mas nem sempre a referida opção padrão é a melhor escolha.

Dessa maneira, ressai evidente que a liberdade de escolhas que permeia a vida social sofre diversos tipos de influências, sendo mais oportuno ao arquiteto de escolhas guiar a comunidade por meio de nudges, em homenagem ao paternalismo libertário, ao invés de socorrer-se a intervencionismo estatal.

\section{TEORIA DOS JOGOS}

É sabido que é da natureza humana a aversão à perda, o que justifica comportamentos de inércia. Assim, a avaliação do jurisdicionado se vai aceitar um acordo ou não passa pela ideia se ele se vai "ganhar" ou "perder". Este padrão de ganhar ou perder é muito relativo, pois deve-se verificar a situação jurídica de modo amplo, ou seja, se ambas as partes estão abertas a uma transação, com concessões mútuas.

Neste sentido, há as expressões como ganha-ganha ou ganha-perde, em uma visão que há duas situações: ou as duas partes ganham, ou uma ganha enquanto a outra perde. Há também a nomenclatura dos jogos de soma zero, de John Von Neumann, em que para a vitória de um, é necessária a derrota do outro, mostrando-se o potencial competitivo do conflito. Já a teoria dos jogos de John Nash, busca exatamente essa visão matemática do resultado materializado no acordo celebrado entre as partes envolvidas, evidenciando seu caráter cooperativo.

Como acima mencionado, a visão de ganhar ou perder não é tão simples e deve ser aferida através de várias nuances do conflito, na saga do Equilíbrio de Nash. Vasconcelos (2017, p. 189) assim explica:

Teoria dos jogos é isso: entender que sua decisão não é independente e ambos os ganhos dependem da combinação de muitas ações em cadeia até chegar em um equilíbrio. Este equilíbrio é o chamado Equilíbrio de Nash, em homenagem a John Nash Jr., prêmio Nobel de 1994, e que foi interpretado por Russel Crowe no filme Uma mente brilhante, ganhador do Oscar de 2002. Por isso que a Teoria dos Jogos é o estado formal das expectativas racionais e consistentes de que os participantes têm sobre as escolhas dos outros É porém, uma denominação matemática, abstrata e dedutiva sobre as condições em que a sua decisão é considerada racional, consistente ou não contraditória, e não um estudo empírico de como as pessoas tomam decisões em um caso concreto.

$\mathrm{Na}$ teoria dos jogos, um elemento importante é o conjunto de jogadores, cada um com seu conjunto de estratégias. "Quando cada jogador escolhe sua estratégia, temos uma 
então uma situação ou perfil no espaço de todas as situações (perfis) possíveis" (SARTINI et al. 2004).

A teoria dos jogos tem aplicação tanto nos meios consensuais, como na esfera judicial, pois nesta hipótese, as regras são ditadas pelo devido processo legal, no curso da situação jurídica existente entre autor, réu e magistrado. Nos meios consensuais, o procedimento é mais flexível e as partes estão mais livres para negociar as fases e número de sessões da mediação, por exemplo.

Cita-se, ainda, a técnica "Chances de Retirada" quando uma das partes demonstra postura dominadora e é necessário, para se manter a boa negociação, que se encontre margem de reserva.

A margem de negociação é uma baliza existente entre o valor de reserva (mínimo) e o valor desejado (ideal), se for considerado valor monetário para um acordo. Cada uma das partes fixa seus parâmetros e a zona possível de acordo (ZOPA) é a intercessão entre a margem do devedor e a do comprador. Desta maneira, é importante que as partes sejam instruídas a estabelecer seus parâmetros, para que seja produtivo o momento das tratativas. Quanto mais avançado e acolhedor é o diálogo entre as partes envolvidas, mais visível fica a zona possível, o que aumentará a possibilidade de êxito.

É interessante destacar, também, a chamada Melhor Alternativa à Negociação de um Acordo (MAANA), que é uma segunda proposta quando o valor desejado não foi alcançado, em homenagem ao comprometimento das partes durante o procedimento. Como forma de garantir a efetiva negociação, o conciliador ou mediador pode até conceder pausas durante o procedimento.

Assim, observa-se o quanto complexa é a decisão a ser tomada quando da elaboração do acordo, em face das várias possibilidades e por isso, o terceiro imparcial deve buscar todas as formas para que as partes conjuntamente cheguem a um consenso através de benefícios mútuos, em postura cooperativa.

Esta veia cooperativa se encontra inserida até mesmo no Novo Código de Processo Civil, precisamente no artigo $8^{\circ}$, que traz para os sujeitos do processo o dever de cooperarem entre si para a busca de uma decisão de mérito justa e efetiva, comportando-se de acordo com a boa-fé, nos termos do artigo $5^{\circ}$ do mesmo diploma legal (BRASIL, 2015).

Há técnicas que podem auxiliar o intermediador nesta busca cooperativa, como a depuração dos bloqueios entre as partes, pois muitas vezes têm cunho psicológico. Ao 
“desarmar" os ânimos, torna-se possível despertar a veia cooperativa dos envolvidos, através de ideias concretas e objetivas.

Garantir a escuta ativa das partes sem interrupções e fazer com que cada um se ponha no lugar e sob as perspectivas do outro são balizadores do terceiro imparcial nos meios consensuais, com vistas a preservar o viés cooperativo.

\section{NUDGES E A INFLUÊNCIA NO LIVRE ARBÍTRIO DOS MEIOS CONSENSUAIS NAS AUDIÊNCIAS JUDICIAIS}

Como já tratado nos tópicos anteriores, os nudges são incentivo para boas opções quando se tem um universo de escolhas a fazer. São estratégias utilizadas para estimular pessoas a seguirem comportamentos socialmente interessantes.

No âmbito do Código de Processo Civil de 2015, o legislador determinou como regra geral a designação de audiência de conciliação e mediação a ser realizada necessariamente por conciliador ou mediador (onde houver) antes da apresentação de defesa por parte do réu. As partes podem optar pela não realização da audiência, e assim, chama-se de "consenso do dissenso", situação em que a audiência será dispensada na forma do art. 334, $\S 5^{\circ}$, CPC (BRASIL, 2015).

Todavia, quando o objeto discutido admite autocomposição e ambas as partes não se manifestaram pela não realização, a audiência deve ocorrer. A legislação processual civil penaliza o não-comparecimento injustificado do autor ou do réu com multa de até dois por cento da vantagem econômica pretendida ou do valor da causa.

Desta forma, em que pesem as discussões doutrinárias acerca da eventual ofensa ao princípio da voluntariedade dos meios consensuais em face à ordem de comparecimento sob pena de multa, o que se verifica é a existência de ônus processual pecuniário na hipótese de ausência de uma das partes à audiência. Ressalte-se que a multa se refere à ausência injustificada à audiência e não à recusa a eventual proposta de acordo que possa ali ser ventilada.

Ora, se a parte perdeu o interesse em comparecer à audiência ou se é apenas um dos envolvidos que não deseja a realização da audiência, a autonomia da vontade permitiria que um dos litigantes pudesse faltar ao ato, pois as partes não podem ser compelidas a permanecer em procedimento autocompositivo, como bem expressa o artigo o art. $2^{\circ}, \S 2^{\circ}$ da Lei $n^{\circ}$ 13.140/2015 (BRASIL, 2015). 
Todavia, pode-se defender a obrigatoriedade de comparecimento como política legislativa, somada ao interesse, ainda que embrionário, de uma das partes em realizar ao acordo e ainda, em homenagem, à estrutura estatal que foi preparada e investida para realizar a audiência de conciliação e mediação, mas desde que haja eleição contratual prévia do instituto da mediação (GUTIERREZ, CUNHA, 2015).

Abstraindo tal discussão, observa-se que independente da posição a ser filiada pelo estudioso, é certo que o Estado adotou postura intervencionista para garantir o fomento dos meios consensuais na esfera judicial. Neste ponto, indaga-se se seria pertinente a adoção do paternalismo liberatório dos nudges.

$\mathrm{Na}$ realidade atual, já é possível destacar algumas iniciativas que demonstram a aplicação de nudges para incentivo dos meios consensuais. Na Justiça Estadual do Estado do Ceará, por exemplo, o Centro Judiciário de Solução de Conflitos e Cidadania (Cejusc) do Fórum Clóvis Beviláqua dividiu suas salas com nomes bem interessantes, que já denotam espírito acolhedor ao jurisdicionado. A mediação pode ocorrer em seis salas, cujos nomes são: superação, justiça, tolerância, sabedoria, harmonia e transformação. Já a conciliação, tem quatro salas, a saber: esperança, cooperação, compreensão e confiança.

Veja-se que a simples atitude de nomear as salas onde serão realizadas as sessões de mediação e conciliação pode ter um efeito positivo sobre a mente do jurisdicionado que se encontra nos corredores do Fórum à espera do pregão de sua audiência.

Outra estratégia hoje já usada é a colocação de avisos motivacionais na sala de audiência ou nos corredores do Fórum, tais como "conciliar é legal", "dissemine a cultura da paz" e "Conciliação: com ela todo mundo ganha. Ganha o cidadão, a justiça e o País".

Como sugestão, pode-se também afixar nos corredores próximos aos Núcleos de Conciliação cartazes mostrando as estatísticas de acordo e seu menor número de descumprimentos se comparado a decisões judiciais, e até mesmo vídeos com depoimentos voluntários de pessoas com experiências positivas como nudges àqueles que aguardam sua audiência e que passam a ter uma visão de valorização no momento da audiência.

A vertente de fomento aos meios consensuais em relação ao Judiciário coaduna-se com a ideia de Mancuso (2009, p. 39) de que:

O Judiciário atuaria como instância residual, e não, como hoje acontece, protagonizando a cena enquanto instância primária, chamado a atuar ainda em meio à eclosão dos conflitos, sobretudo os metaindividuais, os quais poderiam e deveriam passar por um estágio de maturação e tentativa de resolução ou ao menos de equacionamento perante outras intâncias, consultivas ou decisórias, e bem assim, mediante outros meios, auto e heterocompositivos. 
Nas audiências de conciliação e mediação realizadas por terceiro imparcial, é possível verificar que os mediadores e conciliados recorrem ao chamado rapport, que são técnicas de acolhimento como apertos de mãos, preocupações com a temperatura confortável do ambiente para as partes, assim como oferta de água e até mesmo chocolates para que os envolvidos se sintam próximos e bem à vontade para realizar as tratativas de acordo.

O terceiro imparcial deve buscar a postura mais neutra possível, evitando-se a contaminação com as versões das partes para que permaneça evidente e inquestionável sua eqüidistância entre os presentes. As partes devem ser incentivadas a decidir de forma livre e assim, o facilitador deve afastar argumentos de pressão como o de destacar as mazelas do Judiciário como incentivador da permanência nos meios consensuais (SILVA, 2013).

Dessa forma, de um lado está o intervencionismo estatal no que pertine ao comparecimento das partes à audiência de conciliação e mediação sob pena de multa e de outro, a busca de estratégias para que as partes se sintam atraídas para os meios consensuais a fim de que realizem acordos vantajosos e duradouros.

Como Vasconcelos (2017, p. 186) explica, "a tempestade de ideias é uma técnica adotada para a negociação das questões substantivas, para a identificação de interesses e opções." Ao ler o trecho acima, a impressão que se tem é que esta visão já foi relatada neste trabalho, mas com outra nomenclatura. E esta impressão não é equivocada: é que o alvo dos nudges é exatamente a tempestade de ideias e esta avalanche de perspectivas também se vê nas tratativas na audiência de conciliação e mediação.

É oportuno ainda relembrar que a aversão humana à perda na teoria dos jogos, assim como a influência social do comportamento da manada explanada, pode-se observar o quanto a divulgação ampla das vantagens dos meios consensuais é capaz de incentivar pessoas em alterar seu comportamento ao participarem da experiência da mediação ou conciliação.

Imagine-se o quão diferente é o sentimento do demandado, ao receber a carta de citação para comparecimento à audiência de conciliação e mediação que contenha dados estatísticos relativos aos meios consensuais ou até depoimentos de voluntários, ao invés da advertência de pagamento de multa para a ausência injustificada.

Assim, a aplicação de nudges para atrair mais pessoas de forma voluntária ao socorro dos meios consensuais em substituição ao intervencionismo estatal privilegia a cultura de que o Judiciário deve ser a oferta residual do cidadão, ou seja, somente quando não for possível resolver consensualmente uma demanda é que a matéria deve ser submetida ao Poder estatal. 
Esta liberdade deve ser pautada no paternalismo libertário, pois dentro do amplo rol de opções e até de pouco conhecimento por parte de alguns, os nugdes estão a postos para assegurar as opções socialmente recomendáveis. Segundo Thaler e Sunstein (2019, p. 13), “o lado libertário das nossas estratégias se encontra na convicção de que as pessoas devem ter liberdade para fazer o que quiserem, inclusive recusar acordo desvantajosos".

O que se defende nesse trabalho não é a adoção irrestrita aos meios consensuais, mas sim a compreensão de suas vantagens como regra geral e, na hipótese de falharem as tentativas de acordo, as partes devem aguardar decisão judicial e prosseguir com o processo, sem prejuízo de novas tentativas consensuais no curso da ação.

Os nudges acabam por assinalar a perspectiva de uma mudança social no que tange à eleição dos meios consensuais, pois as pessoas poderão escolher voluntariamente e livres de qualquer sanção pecuniária participarem do procedimento de conciliação ou mediação. Assim, o paternalismo libertário traz a ideia do idealizado livre arbítrio da eleição dos meios consensuais, garantindo a plenitude das características destes meios.

A garantia do livre arbítrio no uso dos nudges é assegurada uma vez que "ao implantar adequadamente tanto os incentivos quanto os nudges, aumentamos nossa capacidade de melhorar a vida das pessoas e ajudamos a resolver muitos dos problemas da sociedade. E tudo isso sem impedir a liberdade de escolha de cada indivíduo" (THALER; SUNSTEIN, 2019, p. 17).

Ademais, como os meios consensuais têm por premissa a formação de uma solução duradoura, já que construída pelas próprias partes, a garantia do livre arbítrio conjuga o caráter definitivo do acordo, pois "quando as pessoas concorrem com sua vontade para a construção de uma saída produtiva para ambas, elas cumprem espontaneamente os ajustes entabulados, sendo desnecessário promover iniciativas adicionais para fazer jus ao combinado" (TARTUCE, 2018, p. 193, e-book).

\section{CONCLUSÃO}

O atual Código de Processo Civil privilegiou os meios consensuais na resolução de conflito submetidos ao Poder Judiciário, pois a regra geral é que a contestação somente deve ser apresentada na hipótese de não ter se firmado acordo na audiência de conciliação e mediação. Entretanto, os meios alternativos têm características próprias como a voluntariedade e a garantia legal de que ninguém deverá ser compelido a permanecer em procedimento de mediação. 
A legislação processual civil, na tentativa de dar mais efetividade ao intento acima mencionado, consignou sanção pecuniária que aqueles que faltam injustificadamente à audiência. No presente trabalho, ao estudar o paternalismo libertário e o fenômeno dos nudges, constatou-se que estratégias de incentivo podem envolver pessoas a buscar os meios consensuais de forma livre, sem o temor da imposição de multa.

O intervencionismo empregado para fomentar a participação nas audiências de conciliação e mediação vai de encontro ao espírito dos meios consensuais e assim, nudges são boas práticas para que o jurisdicionado perceba o quão valoroso é a experiência da audiência. Para tanto, pode-se fazer uso de campanhas publicitárias, frases motivacionais e quadros estatísticos nos corredores das salas de audiência, sem olvidar do rapport que evidencia o espírito acolhedor dos mediadores e conciliadores.

O paternalismo libertário permite o amplo uso das técnicas de mediação e conciliação no seu ápice, com o relativismo da ideia do "ganhar" ou "perder", porque as partes estão totalmente livre de temor de qualquer reprimenda. Ao contrário: estão incentivadas a dedicar-se com muito comprometimento àquele procedimento consensual, exaurindo todas as tentativas de solução dos conflitos, cabendo continuar a demanda processual apenas no insucesso da primeira tentativa de acordo, o que evidencia o livre arbítrio.

A maior aplicação dos nudges teria como efeito a tão sonhada mudança de mentalidade social sobre a primazia dos meios alternativos de solução de conflitos, coibindose a vigente cultura demandista, visto que seria mais oportuno e atrativo consignar na carta de citação para comparecimento à audiência de conciliação e mediação as experiências positivas que outras pessoas já tiveram, ao invés de que a parte deve ir ao ato sob pena de multa.

\section{REFERÊNCIAS BIBLIOGRÁFICAS}

BARBOSA, Águida Arruda Barbosa. Mediação familiar interdisciplinar. São Paulo: Atlas, 2015.

BRASIL. Conselho Nacional de Justiça. Manual de mediação judicial. Organização de André Gomma de Azevedo. 6. ed. Brasília, DF, 2016.

BRASIL. Lei n⿳ 13.105, de 16 de março de 2015. Institui o Código de Processo Civil. Brasília, DF: Presidência da República, [2015]. Disponível em: http://www.planalto.gov.br/ccivil_03/_ato2015-2018/2015/lei/113105.htm. Acesso em: 28 maio 2019 
BRASIL. Lei $\mathbf{n}^{0}$ 13.140, de 26 de junho de 2015. Dispõe sobre a mediação entre particulares como meio de solução de controvérsias e sobre a autocomposição de conflitos no âmbito da administração pública; altera a Lei $n^{\circ} 9.469$, de 10 de julho de 1997 , e o Decreto $\mathrm{n}^{\circ} 70.235$, de 6 de março de 1972; e revoga o $\S 2^{\circ}$ do art. $6^{\circ}$ da Lei $\mathrm{n}^{\circ}$ 9.469, de 10 de julho de 1997. Brasília, DF: Presidência da República, [2015]. Disponível em: http://www.planalto.gov.br/ccivil_03/_ato2015-2018/2015/lei/113140.htm. Acesso em: 28 maio 2019.

KAHNEMAN, Daniel. Rápido e devagar: duas formas de pensar. Rio de Janeiro: Objetiva, 2012.

MANCUSO, Rodolfo de Camargo A resolução dos conflitos e a função judicial no Contemporâneo Estado de Direito. São Paulo: Revista dos Tribunais, 2009.

GUTIERREZ, Daniel Mota; CUNHA, Jânio Pereira da. Jurisdição processual e democracia: advento da audiência de conciliação e de mediação, efetivação dos meios equivalentes e acesso à justiça. Revista Opinião Jurídica. Fortaleza. v. 13. n. 17. pp. 108$131,2015$.

SARTINI, Brígida Alexandre e outros. Uma Introdução à Teoria dos Jogos. II Bienal da SBM. Universidade Federal da Bahia, out. 2004. Disponível em:

https://www.ime.usp.br/ rvicente/IntroTeoriaDosJogos.pdf. Acesso em: 24 maio 2019.

SILVA, Érica Barbosa e. Conciliação judicial. Brasília, DF: Gazeta Jurídica, 2013.

TARTUCE, Fernanda. Mediação nos conflitos civis. 2. ed. São Paulo: Revista dos Tribunais, 2015. 4 ed., rev., atual: e amp. Rio de Janeiro: Forense; São Paulo: Método, 2018.

THALER, Richard H.; SUNSTEIN, Cass R. Nudge. Rio de Janeiro: Objetiva, 2019.

VASCONCELOS, Carlos Eduardo de. Mediação de conflitos e práticas restaurativas. 5 ed. rev., atual., e ampl. Rio de Janeiro: Forense; São Paulo: Método. 2017. 